\title{
MEDO DE ERRAR NO AMBIENTE DE TRABALHO DE UM FUNDO DE PENSÃO
}

\section{THE FEAR OF FAILURE IN THE WORK ENVIRONMENT AT A PENSION FUND}

\author{
Edmir Denis Diniz \\ Mestre em Administração \\ Auditor Interno do Banco do Brasil \\ Rio de Janeiro, RJ, Brasil \\ E-mail: edmirdiniz@yahoo.com.br \\ Vinicius Mothé Maia \\ Mestre em Administração \\ Professor FACC/UFRJ \\ Rio de Janeiro, RJ, Brasil \\ E-mail: viniciusmothemaia@yahoo.com.br \\ Patrícia Amélia Tomei \\ Doutora em Administração \\ Professora do Quadro Principal IAG/PUC-Rio \\ Rio de Janeiro, RJ, Brasil \\ E-mail: patomei@iag.puc-rio.br
}

\section{RESUMO}

O medo pode reprimir a criatividade, a inovação e o talento dos indivíduos, sendo capaz de gerar desgostos, frustrações e posturas defensivas. Por outro lado, o medo pode ser interpretado como positivo, e a administração eficaz desse sentimento pode transformá-lo num ponto de apoio de interação social ou fonte de motivação, contribuindo para o desempenho de gerentes e colaboradores de uma organização. O objetivo central deste estudo é analisar como as diferenças geracionais $e$ as variáveis demográficas - tais como gênero, tipo de plano de previdência, nível hierárquico, tempo no cargo e tempo na empresa - influenciam na intensidade do medo de errar no ambiente organizacional. Para tanto, foi aplicado o questionário Performance Failure Appraisal Inventory - PFAI - a uma amostra de funcionários de um Fundo de Pensão do Rio de Janeiro. O tratamento estatístico dos dados revelou baixa intensidade do medo de errar relacionado às gerações, sendo que a Geração $X$ apresentou os maiores índices, colocando em evidência as limitações relacionadas à expressão de sentimentos, principalmente de sentimentos negativos. Por outro lado, gênero e tempo no cargo apresentaram resultados significativos, indicando que mulheres e funcionários em posições hierarquicamente inferiores tendem a sentir com mais intensidade o medo de errar. Esses resultados apontam para a necessidade de uma política de recursos humanos capaz de evitar que esse medo venha a impactar negativamente o desempenho dos funcionários e consequentemente o desempenho organizacional.

Palavras-chave: Medo de errar. Medo organizacional. Gerações. Fundo de pensão.

\section{ABSTRACT}

Fear can restrain creativity, innovation and the talent of individuals, being able to generate disgusts, frustrations and defensive postures. On the other hand, fear can be interpreted as something positive and effective administration of this sentiment can turn it into a foundation of social interaction or source of motivation, contributing to the performance of managers and employees of an organization. The main objective of this study is to examine how generational differences and demographic variables such as gender, type of pension plan, hierarchical level, time in office and time in the company influence the intensity of the fear of failure in the organizational environment. In order to accomplish that, the Performance Failure Appraisal Inventory questionnaire was applied - PFAI - to sample of a Pension Fund employees from Rio de Janeiro. Statistical analysis of the data revealed low intensity of the fear of failure related to generations, and Generation $X$ showed the highest rates, highlighting the limitations related to the expression of feelings, especially negative ones, such as fear. On the other hand, gender and time in office showed significant results, indicating that women and employees in junior positions tend to feel more intensely the fear of making mistakes. These results point to the need for a policy of human resources able to prevent this fear will negatively impact the performance of employees and consequently organizational performance.

Keywords: Fear of failure. Organizational fear. Generation. Pension fund. 


\section{INTRODUÇÃO}

O ambiente organizacional é complexo e, em geral, mutável. A necessidade de administrar constantes mudanças internas é reflexo natural do processo de adaptação das empresas aos desafios impostos por novas tecnologias, transformações sociais, crises econômicas, quebras de paradigmas e uma série de outras forças que pressionam indivíduos e organizações. Num mundo em mutação, os funcionários são estimulados a reavaliar seus conhecimentos, valores e posturas profissionais, num esforço contínuo de ajuste à dinâmica empresarial. A mudança gera e alimenta uma sensação de incerteza que alimenta o sentimento do medo (PEREIRA, 1995).

Tradicionalmente, as pesquisas em finanças se baseiam no pressuposto do homo economicus, ou seja, o modelo de escolhas racionais que assume que os investidores são completamente racionais, equilibrados, sem emoções, em busca da maximização da utilidade esperada com preferências estáveis (FAIRCHILD, 2014). Todavia, em contraste a essa visão, as finanças comportamentais consideram que os investidores do mundo real tomam decisões baseadas na racionalidade limitada - ou seja, a racionalidade baseada nos valores humanos e preferências pessoais -, em opções satisfatórias e com base nas emoções (FAIRCHILD, 2014). É sobre essas emoções, especificamente sobre o medo que esta pesquisa se debruça.

As emoções no ambiente de trabalho ainda são tratadas como atos irracionais e as organizações dão pouco espaço para que as pessoas possam compreendê-las e gerenciá-las (SOUSA, GODOI e VERDINELLI, 2007). Se isto ocorre com os sentimentos em geral, com o sentimento de medo surge uma relação ainda mais negativa. Dentro das organizações, o medo é uma palavra que ninguém gosta de pronunciar ou admitir, mas de fácil identificação (GILLEY, 1999). Em geral, o medo é percebido pelos pesquisadores organizacionais como uma influência negativa, capaz de comprometer a integridade psicológica e até física de quem o vivencia (SUARÉZ, 1993, APPLEBAUM, BREGMAN e MOROZ, 1998). Por outro lado, o medo pode também ser instrumento de motivação já que como afirma Dejours (1992), ele serve à produtividade e é utilizado em larga escala pelos gestores.

Existem diversos tipos de medo como, por exemplo, o medo de altura, de falar em público, de animais, mas especificamente o medo de errar pode ser considerado um dos principais tipos de temor presentes no ambiente organizacional (SUARÉZ, 1993). É um tipo de sentimento capaz de provocar postura defensiva, apatia, queda de produtividade, aversão ao novo e, por fim, limitar a criatividade. Gerenciar esse tipo de emoção pode ser inevitável.

Portanto, neste trabalho buscamos entender a seguinte questão: como o medo de errar se manifesta no ambiente de trabalho de um Fundo de Pensão e como a sua intensidade varia nas diferentes gerações?

A ênfase do estudo está no esforço em compreender como a intensidade do medo de errar varia segundo as diferentes gerações presentes em uma empresa fechada de previdência complementar, aplicando o instrumento de mensuração denominado "The Performance Failure Appraisal Inventory" (PFAl) (CONROY, 2002). Esse instrumento foi empregado devido a sua utilização em outras pesquisas, tendo sido valido e aprimorado por Conroy ao longo de seus estudos.

O conceito de medo de errar definido por Conroy (2002) e empregado no questionário PFAI baseiase no conceito postulado por Birney, Burdick e Teevan (1969). Nesse contexto, o sentimento do medo de errar é decomposto em cinco dimensões: Vergonha e Constrangimento, Desvalorização da Autoestima, 
Incerteza sobre o Futuro, Perda de Interesse de semelhantes de importância e Afetar Negativamente semelhantes de importância.

Os gestores dos fundos de pensão são avaliados a todo o momento, não apenas por pesquisadores (FONSECA et al., 2007), mas também pelo mercado. Além disso, os fundos de pensão vem se expandido ao longo dos anos, a carteira consolidada de ativos desses fundos no Brasil em 2013 registrou R $\$ 640,3$ bilhões, equivalente a 13,8\% do PIB (ABRAPP, 2013). Atribui-se aos fundos de pensão uma responsabilidade na geração de valor e nos rumos dos segmentos produtivos do país pelo elevado montante de capital investido em participação acionária nas empresas brasileiras. Cria-se uma expectativa sobre os gestores desses fundos, não sendo aceito o erro. Sendo assim, é de se esperar um pressão sobre esses gestores e uma consequente necessidade de se gerir esse medo.

Pesquisas comprovam que o medo gera consequências diretas no ambiente de trabalho (APPLEBAUM, BREGMAN e MOROZ, 1998; DEJOURS, 1995; SUARÉZ, 1993) e investigar suas influências pode oferecer à organização informações importantes sobre as necessidades, desejos e expectativas das pessoas e contribuir para a elaboração de políticas gerenciais e comportamentais. Os resultados alcançados por essa pesquisa podem auxiliar os líderes da organização a compreender um fator subjetivo e apontar um caminho para transformá-lo em instrumento gerencial, impactando positivamente o desempenho organizacional.

\title{
REVISÃO DA LITERATURA
}

\section{Conceituando Medo}

De acordo com o Dicionário Michaelis, por medo tem-se:

\begin{abstract}
"1 Perturbação resultante da ideia de um perigo real ou aparente ou da presença de alguma coisa estranha ou perigosa; pavor, susto, terror. 2 Apreensão. 3 Receio de ofender, de causar algum mal, de ser desagradável. Gestos ou visagens que causam susto."
\end{abstract}

"Perturbação", "ideia", "pavor", "apreensão", "receio". Tais palavras mostram que o "medo" trata de um sentimento, de uma emoção. As emoções são fenômenos complexos e objetos de análise por diversas áreas do conhecimento com diferentes perspectivas. As emoções possuem um caráter individual na medida em que envolvem uma avaliação do indivíduo sobre uma situação vivida (FRIJDA, 2000). Mas também, para Seymor (1980), a emoção pode ser considerada como uma síndrome socialmente construída, baseada nas percepções do indivíduo sobre determinada situação.

Lopéz (1972) define o medo como um uma série de fenômenos sucessivos de paralisação ou cessação do curso vital que ocorre nos seres vivos - desde os mais simples, até os mais complexos - ao se perceberem submetidos a bruscas ou desproporcionadas modificações ambientais. Ele assinala três formas de medo: o instintivo, o racional e o imaginativo e registra sua evolução nos seres humanos em quatro fases.

O medo instintivo, nas palavras do próprio autor, "é um medo mais tido, do que sentido, do que pensado". É a forma mais primitiva do sentimento, caracterizada pela baixa no metabolismo vital frente às ações nociceptivas - maléficas - diretas e imediatas. Trata-se de um medo reativo, percebido "a posteriori". 
"Quando chega aos centros corticais, a onda de estímulo, já determinou antes diversos reflexos e inibições nos níveis medulares e subcorticais" (LOPÉZ, 1972).

O medo racional, por sua vez, é um medo "profilático". Tal reação às ações nociceptivas é condicionado por experiências prévias e tem bases racionais. É um medo que se faz compreensível até para quem não o sente diretamente. Dessa forma, por ser lógico, tal padrão fobígeno é passível de transmissão. O indivíduo pode não temer algo, mas ao tomar ciência dos danos que tal coisa poderia causar, passa a temêla.

O medo imaginário, finalmente, é considerado a "variedade mais torturante das formas de atuação do Gigante Negro". Isso porque as ações nociceptivas que seriam o ponto de partida deste tipo fobígeno nunca consistiram de fato numa causa de medo orgânico, propriamente dita. Daí, o indivíduo, por meio de uma rede fluida e precariamente estruturada de associações, amedronta-se. Dessa forma, o medo imaginário é injustificado e incompreensível.

Alguns outros autores também apresentam pontos bastante relevantes quanto ao tema. De acordo com Riezler (1944) o medo é uma constante na experiência humana. Segundo ele, indivíduos passam a vida oscilando entre dois extremos: medo e esperança. Ele diferencia medos como definidos e indefinidos. O que diferencia os dois tipos de medo é o quanto o indivíduo tem de conhecimento sobre o agente fobígeno e consegue estruturar mentalmente um sistema de escape da situação que the causa pavor. A estes últimos os medos indefinidos - ele os chama de "ansiedade", que seria um medo sentido por/de nada e que em casos extremos, poderia angustiar tanto o indivíduo a ponto de levá-lo ao suicídio.

Em Day (1970), a relação entre medo e esperança também foi utilizada. No modelo conceituado por ele, " $A$ " representa o indivíduo amedrontado e " $P$ ", o agente fobígeno. " $A$ ' teme que ' $P$ ' seja real, se e somente se ' $A$ ' tenha aversão em algum grau, mesmo que pequeno, que ' $P$ ' e acredita que seja provável em algum grau, mesmo que pequeno, que ' $P$ ' seja real'.

Em síntese, o medo seria a resultante de uma aversão e uma probabilidade à ela relacionada.

\section{O Medo no Contexto Organizacional}

Jean Paul Sartre (2010) afirmou: "Todos os homens têm medo. Quem não tem medo não é normal; isso nada tem a ver com a coragem". Igual a Sartre, a reflexão sobre o medo foi denominador comum de pensadores, artistas, atletas e muitos outros e será o tema que inspira este trabalho.

São muitos os agentes causadores de medo existentes no ambiente de trabalho contemporâneo. Mudanças tecnológicas e constantes transformações nos sistemas de gestão têm aumentado as pressões por excelência, assim como pela produtividade, intensificando dessa forma a experiência profissional (CUNHA, 2006).

Tal fato, na maioria dos casos, é percebido pelos pesquisadores organizacionais como algo danoso, capaz de comprometer a integridade psicológica e até física de quem o vivencia, influenciando negativamente o funcionamento organizacional (SUAREZ, 1993, APPLEBAUM,BREGMAN, MOROZ, 1998). 
$\mathrm{Na}$ literatura organizacional o tema não é tratado de forma exaustiva, mas alguns trabalhos teóricos relacionados a questão são significativos. Identificamos a seguir as pesquisas de:

1) Koury (2002) que assinalam que o medo como um construto social é uma das principais peças estruturadoras da vivência em grupo. Segundo o autor, o medo adquire no cotidiano de sua ação um caráter de organizador social e é fundamental para a assimilação de embates de configuração e de processos de sociabilidade e formação de instrumentos de ordem e desordem, Nesse cenário, indivíduos temem pela sobrevivência, integração e adequação a perfis já consolidados, numa forma de imposição associativa, com normas específicas a serem seguidas e disseminadas para as futuras gerações.

2) Wilson e Edmondson (1991) nas quais os autores associam diversos tipos de medos à posição hierárquica, à autoridade, ao poder e a fatores psicológicos sociais

3) Applebaum, Bregman e Moroz(1998) que identificam o medo de mudanças organizacionais e o medo de tomadas de decisões arriscadas como os principais medos no ambiente de trabalho e enfatizam que a punição e o medo estão intimamente correlacionados e profundamente enraizados no inconsciente dos membros organizacionais. Segundo o autor, apesar de estar comprovado que um ambiente ideal deve favorecer a livre expressão de ideias e potenciais isentas de medo, muitos comportamentos e práticas organizacionais são contraditórias.

4) Castelhano (2005) que assinalam que o medo no ambiente organizacional se instala no psiquismo do sujeito como um sinal contra o perigo, imposto pela lei e pela autoridade.

5) Dejours (1992) que ressaltam que o medo é uma das dimensões da vivência dos trabalhadores muitas vezes ignorada no campo de pesquisa da psicopatologia e está presente em todos os tipos de ocupações profissionais. Para o autor, o medo serve à produtividade e é utilizado em larga escala pela gestão organizacional.

6) Applebaum, Bregman e Moroz (1998) que utilizam o medo como uma estratégia organizacional, com reforços positivos e de punições.

7) Suaréz (1993) que definem o medo como uma sensação desagradável que é acompanhada de reações psicológicas, cognitivas e comportamentais. Nos seus estudos, o autor apresenta uma classificação de sete tipos de medos que ocorrem no ambiente de trabalho: medo de repreensão e de críticas negativas, medo de sucesso; medo de novo conhecimento; medo de mudança; medo de falar; medo de não se destacar, e medo de errar.

Neste trabalho verticalizaremos a análise neste último tipo de medo que segundo Suaréz (1993) está relacionado ao medo de repreensão e de críticas negativas e diminui severamente a propensão de tomadas de decisão arriscadas, já que o indivíduo desenvolve uma postura defensiva, cética e apática. 


\section{O Medo de Errar e suas Consequências}

Os primeiros artigos acadêmicos relacionados ao tema são de teóricos comportamentais como Murray (1938) e McClelland et al. (1953) que partindo de uma perspectiva unidimensional afirmavam que o medo de errar do indivíduo não estaria no fato de não cumprir um determinado objetivo pré-estabelecido. A razão do temor, verdadeiramente, seria com as consequências de tal fracasso que então, poderiam ser resumidas em vergonha e humilhação.

A vergonha está associada ao sentimento de desonra, humilhação ou de uma situação de afronta, podendo gerar marcas definitivas no indivíduo. A reação mais comum de um sujeito envergonhado é sua intenção de passar despercebido por determinadas situações sociais. A pessoa sente-se exposta e vulnerável. Segundo Gaulejac (2006), a vergonha é um sofrimento social e psíquico particularmente doloroso. A humilhação gerada pode levar o ser humano ao silêncio diante das violências sofridas, a se fechar em si, a cultivar o sentimento de ilegitimidade.

Ser exposto ao ridículo é causa de humilhações que por sua vez afeta a vaidade. Fugir da vergonha e das circunstâncias que podem ocasioná-la é cada ação corriqueira no ambiente organizacional. Ainda segundo Barreto (2000), a humilhação constitui um risco invisível, porém concreto nas relações de trabalho, revelando-se como uma forma de violência sutil nas relações organizacionais, sendo mais frequente com as mulheres e adoecidos.

A vergonha afeta diretamente a autoestima, entendida como um conjunto de sentimentos e pensamentos do indivíduo sobre seu próprio valor, competência e adequação, refletindo uma atitude positiva ou negativa em relação a si mesmo. O ponto fundamental da autoestima é o aspecto valorativo, o que influencia na forma como o indivíduo elege suas metas, aceita a si mesmo, valoriza o outro e projeta suas expectativas para o futuro (SBICIGO, BANDEIRA e DELL'AGLIO, 2010).

Esta perspectiva unidimensional do medo de errar é a mais comum até os dias de hoje e converge na ampla produção acadêmica acerca do sentimento de vergonha e seus efeitos nos indivíduos, resultado de uma tentativa frustrada de realizar algo (ELIOTT, 2004). Vários estudos abordam como o sentimento de vergonha compromete de maneira incisiva a percepção do indivíduo sobre si próprio (LEWIS,1992) e como a sensação de exposição negativa frente a seus semelhantes faz com que sensações de desapreço, desvalorização e iminência de abandono venham à tona (ANDREWS, 1995).

Embasado numa perspectiva multidimensional para a análise do medo de errar autores como Birney, Burdick e Teevan (1969) partiram da premissa de que as consequências dos erros seriam percebidas de maneira negativa pelos indivíduos. Assim sendo, propuseram um modelo que decompôs o medo de errar em três dimensões: desvalorização da autoestima, punições não-egocêntricas - "nonego punishment" (BIRNEY, BURDICK e TEEVAN, 1969) e redução do valor social.

O psicólogo norte-americano David Conroy, tendo como base o trabalho de Birney, Burdick e Teevan (1969) e com o intuito de postular um instrumento de mensuração do medo de errar, desagregou hierarquicamente este conceito em cinco dimensões (CONROY, 2002): experiência de vergonha e constrangimento (o indivíduo sente-se envergonhado e constrangido após o erro), desvalorização da autoestima (a autoestima do indivíduo é diminuída, como consequência do erro), sensação de incerteza sobre o futuro(para o indivíduo, seu futuro passa a ser incerto após o erro), perda de interesse de semelhantes de 
importância (aqueles que são importantes ao indivíduo perdem o interesse nele, devido ao erro) e afetar negativamente semelhantes de importância(semelhantes de importância ao indivíduo sofreriam consequências negativas sobre o seu erro)

O medo de errar, de maneira genérica, é relacionado às consequências bastante negativas, tanto físicas, quanto mentais como: o aparecimento de uma postura defensiva/pessimista no indivíduo, além de limitá-lo em suas habilidades (ELLIOT e CHURCH, 2003), altos níveis de ansiedade (ELLIOT e MCGREGOR, 1999), atenção difusa, desconforto (DULEY et al., 2005), adoção de um perfil de fuga de desafios (CONROY e ELLIOT, 2004) e estresse ao relacionar-se com outros indivíduos (CONROY, ELLIOT, e PINCUS, 2009)

Temer pelo futuro é um sentimento próximo ao medo da morte. Para Riezler (1944), o medo dos indivíduos pela morte se mistura com o medo de sofrer ao morrer e com o medo do que acontecerá após a morte. A falta de controle e informação sobre o que pode acontecer incita mais ainda este processo imaginativo, podendo potencializar a sensação do medo. No objetivo de impedir o medo de controlá-lo, acarretando no aparecimento de uma possível paranoia, o homem, sabendo que a morte é inevitável, evita o pensamento excessivo sobre ela. O ser humano acaba por dirigir seus sentimentos no intuito de viver o melhor possível sua vida, reprimindo, assim, seu medo de morrer (RIEZLER, 1944). No ambiente organizacional não é muito diferente. Há uma combinação de sentimentos no que diz respeito à palavra demissão. $O$ indivíduo tem medo de ser demitido, e este sentimento é composto por uma mistura entre o medo de sofrer ao ser demitido e o medo do que irá acontecer com sua vida após sua demissão. Mas, mesmo sabendo que um dia poderá perder seu emprego, este indivíduo concentra-se em seu trabalho, esquivando-se de pensar diariamente neste medo pela demissão (PEREIRA, 2006).

O homem é um ser social que frequentemente se vê através dos olhos de seu semelhante. Grande parte do autoconhecimento pode ser influenciada pelos outros (ARONSON, WILSON e AKERT, 2012). As pessoas tendem a se apresentar de modo diferente perante os semelhantes. Além disso, a maneira como o outro percebe o indivíduo é capaz de moldar a definição que esse indivíduo faz de si mesmo. É como se as outras pessoas segurassem um espelho que reflete a imagem que elas formam do indivíduo. A capacidade de olhar para si mesmo através dos olhos de outro ser humano é crucial para o desenvolvimento do senso de si mesmo. Permite compreender que é possível ver o mundo de uma maneira diferente daquela como os outros o veem. Se o homem deseja verificar quais são seus sentimentos, seus traços de caráter e suas habilidades, outras pessoas e seus sentimentos, seus traços e habilidades constituem valiosa fonte de informação (ARONSON, WILSON e AKERT, 2012). A fonte de comparação mais simples e acessível é o próprio semelhante. Numa sala de aula, os outros membros da classe. Numa organização, os colegas de trabalho. Assim, o erro cometido afasta o indivíduo, dentro de sua perspectiva, do seu semelhante, na medida em que o coloca num patamar inferior.

Aronson, Wilson e Akert (2012) ensina que o homem sente necessidade de considerar a si mesmo sensato, moral e inteligente. Quando uma pessoa é confrontada com informações indicando que seu comportamento foi irracional, imoral ou estúpido, ela experimenta um grande desconforto, denominado dissonância cognitiva. Trata-se de uma reação poderosa e perturbadora. Em geral, o indivíduo busca reduzir a dissonância mudando o comportamento ou tentando justificá-lo.

A semelhança entre pessoas constitui uma causa poderosa de atração e estima. A maneira como o indivíduo se sente a respeito de seus relacionamentos depende da percepção das trocas que ele faz com os 
outros, em termos de recompensas e custos. Alguns teóricos defendem a ideia que as pessoas são mais felizes quando a taxa de benefícios e custos experimentados é aproximadamente igual ao dos colegas e parceiros (ARONSON, WILSON e AKERT, 2012).

\section{As Gerações no Ambiente Organizacional}

O conceito de gerações baseia-se no fundamento de que os indivíduos partilham valores e comportamentos comuns, configurando grupos distintos em uma organização (TOLBIZE, 2008). Outra abordagem avalia que as pessoas em um mesmo estágio de carreira, independente de geração, aspiram desejos semelhantes em seus empregos (JURKIEWICZ e BROWN, 1998) e tentar fazer uma separação dos empregados entre gerações pode ser um equívoco (JORGENSEN, 2003).

Para Veloso, Dutra e Nakata (2008), as organizações modernas precisam lidar com as diferentes idades dos seus membros, pressupondo comportamentos característicos para cada faixa etária, com diferenças de atitudes em relação à vida e ao trabalho. A existência de uma força de trabalho composta de diferentes gerações pode comprometer a retenção e motivação dos indivíduos, apresentando-se como desafio para a política de recursos humanos, além de elevar os esforços de desenvolvimento de pessoas. Os grupos etários dentro das organizações reagem de forma específica aos programas desenvolvidos e possuem diferentes expectativas. Cada geração possui peculiaridades que afetam a ética no trabalho, os relacionamentos, o modo de administrar as mudanças (GLASS, 2007).

Segundo Crampton e Hodge (2009), há o entendimento geral de que a força de trabalho está dividida em quatro grupos distintos, variando um pouco o período de início e fim de cada geração: Veteranos (nascidos de 1925 a 1945); Baby Boomers (nascidos de 1946 a 1964); Geração X (nascidos de 1965 a 1979); e Geração Y (nascidos de 1980 a 1999). Os Veteranos passaram por crises e guerras e são muito disciplinados com relação a regras e regulamentos. Seus descendentes, os Baby Boomers, nasceram após a segunda guerra mundial e viveram em sua juventude uma época de prosperidade. Tendem a aceitar a mudança com relativa facilidade, são altamente comprometidos com o trabalho e leais aos seus empregadores. Respeitam a autoridade como os veteranos, mas gostam de serem tratados como iguais. São também caracterizados como pessoas que acreditam que o trabalho duro e sacrifício são o preço a pagar para o sucesso, gostam do trabalho em equipe, mas não toleram feedback constante (TOLBIZE, 2008). Boomers têm sido descritos como tendo um senso de direito e hábeis em relacionamentos, sendo relutantes em discordar de colegas e julgamentos de outros que não veem as coisas à sua maneira (ZEMKE, RAINES e FILIPCZAK, 1999). O trabalho de Tomkiewiczand e Bass (2008) apresentou resultados que divergem do entendimento geralmente aceito de que trabalhadores mais jovens preferem ser gerenciados por gestores também jovens. A pesquisa indicou que os funcionários se sentiram valorizados pelos gerentes mais velhos e em contraste, os gestores mais jovens deram a impressão de serem ambiciosos e apenas preocupados com o desempenho e a utilização de recursos.

Glass (2007) aponta que, nos EUA, alguns pais dos membros da Geração X experimentaram uma das primeiras rodadas de demissão em massa nas empresas nos anos 1980, o que permitiu alterações do ponto de vista da geração em relação ao trabalho. Quando crianças foram ensinadas a serem indivíduos autossuficientes. Assim, buscam maior equilíbrio entre trabalho e vida pessoal o que pode ser interpretado 
como egoísmo. Desconfiados das organizações, os indivíduos da geração $X$ são menos fiéis as empresas do que os das gerações anteriores. Os empregados da Geração X são rotulados algumas vezes de "preguiçosos", pois trabalham apenas as horas necessárias ou um pouco mais (TOLBIZE, 2008). Os indivíduos da Geração X demonstram ser céticos e politicamente apáticos, refletindo as frustrações da geração anterior. Gostam da informalidade no trabalho e buscam o equilíbrio entre a vida profissional e pessoal, além do gosto pela tecnologia e pelo consumo de equipamentos eletrônicos. Trabalham com empenho quando possuem foco definido. Para Veloso, Dutra e Nakata (2008) os elementos que a Geração $X$ procura desenvolver são habilidades para gerar empregabilidade, pois perceberam que lealdade não implica em estabilidade. Outras características dos indivíduos da geração $X$ apontadas em diversos trabalhos acadêmicos (TOLBIZE, 2008): o gosto pela variedade, evitando a rotina do dia a dia; a preferência por metas de carreira dirigidas a novos desafios e oportunidades; a crença no crescimento, no aprendizado, na aquisição de novas habilidades sendo aplicadas num ambiente de equipe como a melhor maneira de garantir-se no trabalho; autoconfiança, espírito empreendedor, desafio ao status quo, busca pela maneira aperfeiçoada de realizar as tarefas; a preferência por feedbacks regulares e frequentes sobre o desempenho de seu trabalho.

A Geração Y, também denominada Geração do Milênio, Geração WWW, Geração Digital, Geração Net (CRAMPTON e HODGE, 2009; TOLBIZE, 2008), tem por característica a vontade de inovar, de ter significado, de conciliar o trabalho com uma boa qualidade de vida, o desejo de poder ter um trabalho que faça sentido, um ambiente alegre, senso de importância e pertencimento. A geração $Y$ é a geração que hoje está se inserindo no mercado de trabalho e começando a influenciar os destinos das organizações e da sociedade. Ocuparão os cargos de gestão, mudando a forma de realizar os negócios no cenário contemporâneo e serão os líderes do futuro (OLIVEIRA, 2010).

Segundo Glass (2007), os indivíduos da Geração Y gostam de receber feedback, característica ligada ao forte envolvimento emocional com os pais. Para essas pessoas, se o trabalho é avaliado constantemente, se são fornecidas instruções detalhadas das suas tarefas, a satisfação é maior. Associado ao feedback, a comunicação também é central para eles. Considerados nativos tecnológicos, os indivíduos desta geração preferem usar mensagens de texto, correios eletrônicos e outras formas de comunicação instantânea (GLASS, 2007).

A informalidade na comunicação é característica marcante. A forma de se relacionar com todas as hierarquias nas organizações, independente do título ou posição, pode ser vista como insubordinação em alguns casos, mas é reflexo de uma forma não convencional de se enxergar a estrutura organizacional. $O$ trabalho não é uma atividade dissociada do restante de sua vida. Desejam fazer parte de um propósito maior e de aprender coisas novas. A Geração $Y$ é obcecada pelo desenvolvimento da carreira e acredita que as promoções devam ser baseadas preferencialmente na competência (GLASS, 2007).

As diferenças expostas entre as gerações evidenciam os contrastes existentes na maneira delas atuarem e encararem o ambiente organizacional. Essas diferenças podem influenciar como cada uma das gerações lida com seus temores dentro da organização. 


\section{Fundos de Pensão no Brasil}

Carvalhal (2006) relata que a partir da década de 1990, os fundos de pensão passaram a ter participações acionárias permanentes e relevantes em empresas nacionais e começaram a variar suas formas de ação, visando ganhar valor no longo prazo por meio de uma postura ativa no monitoramento dos negócios das empresas investidas.

A partir do fim da década de 1990, grande parte das empresas brasileiras que ofereciam plano de previdência complementar a seus funcionários encerrou a adesão aos planos de benefício definido e criaram planos de contribuição definitiva. Nesse tipo de plano, a gestão de risco e retorno dos ativos é primordial para proporcionar um melhor valor de benefício a seus associados, pois não há garantia de recebimento certo de parte do salário pelo plano.

No Brasil, os maiores fundos de pensão monitoram a gestão das empresas em virtude das participações expressivas no capital das companhias, o que diminui a mobilidade no mercado sem influenciar os preços das ações. Dessa forma, estes se configuram em investimentos de longo prazo, o que implica uma atuação participativa e necessidade de análises criteriosas para tomada de decisão.

Carvalhal (2006) aponta que alguns fundos de pensão contrataram empresas especializadas para seus conselheiros aperfeiçoarem seus conhecimentos. Alguns deles aprovaram critérios para indicação de diretrizes e de normas de atuação para os membros do conselho de administração e do conselho fiscal. Além disso, vem ocorrendo uma troca de experiências entre as entidades nacionais e órgãos reguladores e fundos de pensão internacionais, o que tende a aprimorar as boas práticas brasileiras.

A Resolução $n^{\circ}$ 3792, de 24 de setembro de 2009 do Conselho Monetário Nacional, publicada pelo Banco Central, ampliou a alocação máxima em renda variável por faixas conforme segmento de adesão de governança da BM\&FBovespa para os Fundos de Pensão. O limite permitido para investimentos em carteira de companhias que aderiram ao Novo Mercado é de até $70 \%$ por plano de benefícios. O limite em ações com adesão ao Nível 2 é de até $60 \%$, para o Bovespa Mais até $50 \%$, para empresas no Nível 1 até $45 \%$ e para empresas sem adesão no máximo $35 \%$.

Observa-se, portanto, um incentivo para ampliação de seus investimentos em renda variável. Os fundos de pensão, como administradores de planos de previdência, possuem como um de seus principais desafios tornarem eficiente a relação risco e retorno de seus investimentos para proporcionar melhores benefícios a seus associados. Assim, se a estratégia for de ampliar a alocação em renda variável, mais pressão e cobrança recairá sobre os funcionários dessas entidades. Nesse sentido, espera-se que os resultados da pesquisa possam suprir os gestores de recursos humanos com informações relevantes para que as demandas crescentes sobre os funcionários não impactem negativamente o desempenho dessas organizações. 


\section{METODOLOGIA}

Do ponto de vista de sua natureza, uma pesquisa aplicada procura gerar conhecimentos dirigidos à solução de problemas específicos. Envolve verdades e interesses locais. Do ponto de vista da forma de abordagem do problema, uma pesquisa quantitativa considera que tudo pode ser quantificável, o que significa traduzir em números opiniões e informações para classificá-las e analisá-las, utilizando recursos e técnicas estatísticas. Quanto aos fins, uma pesquisa é considerada uma investigação exploratória se é realizada em área na qual há pouco conhecimento acumulado e sistematizado. Por sua natureza de sondagem, não comporta hipóteses que, todavia, poderão surgir durante ou ao final da pesquisa. Quanto ao meio de investigação, um estudo de caso é aquele circunscrito a uma ou poucas unidades, entendidas essas como uma pessoa, uma família, um produto, uma empresa, um órgão público, uma comunidade ou mesmo um país. Tem caráter de profundidade e detalhamento. Pode ou não ser realizado no campo (GIL, 2002). Assim, o presente trabalho pode ser caracterizado como uma pesquisa exploratória circunscrita a um caso único, sendo a unidade de análise uma entidade fechada de previdência complementar. A pesquisa se deu então em três passos, primeiro na coleta de dados, em seguida a aplicação dos testes estatísticos e por fim a análise dos resultados

O universo desta pesquisa pertence ao ambiente organizacional de uma entidade fechada de previdência complementar, com sede no Rio de Janeiro. Trata-se de um dos maiores fundos de pensão da América Latina, cuja responsabilidade é administrar e conceder benefícios previdenciários aos funcionários de uma empresa de economia mista, denominada Patrocinador. A escolha de um Fundo de Pensão se deu devido a relevância em se estudar o medo em uma empresa do setor financeiro que administra um alto montante, sendo o medo de errar uma questão relevante para os gestores de recursos humanos em suas políticas. Além disso, o acesso facilitado ao universo de pesquisa viabilizou a realização do estudo.

Os dados da pesquisa foram coletados em 2014 quando o Fundo contava com 518 funcionários cedidos pelo Patrocinador. Aos 518 funcionários da empresa com contrato de cessão foi encaminhado um link, via e-mail corporativo, contendo o acesso a uma versão traduzida para o português pelos autores do questionário "The Performance Failure Appraisal Inventory" (PFAI), a fim de obter os índices do medo de errar, bem como as informações demográficas relativas a idade, cargo, tempo no cargo e tempo na empresa. O preenchimento do questionário e das informações demográficas se deu após uma breve explicação sobre a proposta da pesquisa e da forma correta de preenchimento do documento, tomando como referência a experiência dos respondentes no ambiente organizacional. No total, foram obtidas 217 respostas. As informações coletadas foram tabuladas e tratadas estatisticamente através de softwares específicos.

O conceito de medo de errar definido por Conroy (2002) e do questionário PFAI baseia-se no conceito postulado por Birney, Burdick e Teevan (1969). O sentimento do medo de errar foi decomposto em cinco dimensões. São elas: Vergonha e Constrangimento (VC), Desvalorização da Autoestima (DA), Incerteza sobre o Futuro (IF), Perda de Interesse de semelhantes de importância (PI) e Afetar Negativamente semelhantes de importância (NA).

A versão do questionário PFAl utilizada nesta pesquisa possui 25 itens (CONROY, 2002). São afirmativas às quais os respondentes devem indicar numa escala Likert de cinco pontos - com valores estabelecidos entre (-2) e (+2), onde o primeiro indica total discordância com a afirmação e o segundo, total 
concordância. O valor (0) denota indiferença e os valores (-1) e (+1) são pontos intermediários para a discordância e concordância, respectivamente.

O cálculo do índice geral do medo de errar foi obtido através da média das respostas dos 25 itens do questionário PFAI. E quanto às dimensões, o índice é obtido através da média das respostas às perguntas correspondentes. Os índices obtidos foram relacionados às variáveis demográficas.

A fim de traçar o perfil da amostra selecionada, os dados tabulados foram tratados com técnicas de estatística descritiva para aferir frequências, médias e desvios padrões. Quanto aos dados coletados através do PFAI, de início, foi realizado um teste de consistência da versão do questionário utilizada nesta pesquisa através do Alfa de Cronbach, medida de consistência interna que possibilita constatar se todos os itens que o compõem foram compreendidos e se tais dados são confiáveis.

Após o teste de consistência, seguiu-se uma análise de correlação. O objetivo foi descobrir se existe um relacionamento entre as variáveis, além de mostrar o grau de relacionamento, a direção e o nível de probabilidade associada.

A fim de aferir a normalidade da distribuição dos índices do medo de errar foi realizado o teste Kolmogorof-Smirnov. Confirmada a normalidade, as questões foram testadas através do método de análise de variância (ANOVA), observando seus requisitos intrínsecos: a normalidade da distribuição da amostra, homocedasticidade e aleatoriedade e independência dos erros. Tal procedimento foi realizado considerando nível de confiança de $95 \%$.

Para verificar como a intensidade do medo de errar (geral e as cinco dimensões) varia de acordo com as diferentes gerações e em relação às faixas etárias (independente da geração), foram desenvolvidas, para cada dimensão e para o índice geral, 11 ANOVA's One-Way, uma para cada variável (ou interação) de interesse. Foi considerada uma significância de $5 \%$.

Os resultados foram tabulados e apresentados aos leitores. Primeiramente são expostos a estatística descritiva das características socioeconômicas da amostra e a percepção do medo, para que se possa tomar conhecimento dos dados. Em seguida são apresentados os resultados dos testes de normalidade e correlação entre as variáveis. Por último, é apresentado o resultado dos ANOVAs. 


\section{RESULTADOS}

\section{Perfil da amostra}

No total, foram obtidas 217 respostas. Para demonstrar o perfil da amostra foram considerados somente os questionários completos, totalizando 129. A idade média dos respondentes teve o valor de 41,15, num range com idades entre 21 a 60 anos de idade. A distribuição da frequência das idades pode ser observada na Tabela 1.

Tabela 1 - Distribuição de frequência das idades na amostra.

\begin{tabular}{cccc}
\hline Idade & Frequência & Porcentagem & Porcentagem Cumulativa \\
\hline 21 a 30 & 16 & 12,4 & 12,4 \\
31 a 40 & 45 & 34,9 & 47,3 \\
41 a 50 & 47 & 36,4 & 83,7 \\
51 a 60 & 21 & 16,3 & 100,0 \\
Total & 129 & 100,0 & \\
\hline
\end{tabular}

Fonte: elaborada pelos autores.

Quanto ao pertencimento às Gerações Baby Boomers, X e Y, foi utilizada a definição de Cramptone e Hodge (2009) quanto à ordem cronológica de início e término dos períodos geracionais: Veteranos: nascidos de 1925 a 1945; Baby Boomers: nascidos de 1946 a 1964; Geração X: nascidos de 1965 a 1979; Geração Y: nascidos de 1980 a 1999. Assim, em relação à amostra os resultados são expostos na Tabela 2.

Tabela 2 - Número de funcionários por geração na amostra.

\begin{tabular}{ccc} 
& Definição & Amostra \\
\hline Tipo & Data de Nascimento & Número de Funcionários \\
\hline Baby Boomers & 1946 a 1964 & 21 \\
Geração $X$ & 1965 a 1979 & 92 \\
Geração $Y$ & 1980 a 1999 & 16 \\
\hline
\end{tabular}

Fonte: elaborada pelos autores. 
Em relação ao gênero, plano de previdência, cargo, tempo no cargo e tempo no Fundo de Pensão, os resultados são apresentados nas Tabelas 3 a 7.

Tabela 3 - Distribuição de homens e mulheres na amostra.

\begin{tabular}{cccc}
\hline Gênero & Frequência & Porcentagem & Porcentagem Cumulativa \\
\hline Maculino & 72 & 55,8 & 55,8 \\
Feminino & 57 & 44,2 & 100,0 \\
\hline Total & 129 & 100,0 & \\
\hline
\end{tabular}

Fonte: elaborada pelos autores.

Tabela 4 - Distribuição dos funcionários por tipo de plano previdenciário na amostra

\begin{tabular}{cccc}
\hline Plano Previdenciário & Frequência & Porcentagem & Porcentagem Cumulativa \\
\hline Plano 1 & 54 & 41,9 & 41,9 \\
Plano 2 & 75 & 58,1 & 100,0 \\
\hline Total & 129 & 100,0 \\
\hline
\end{tabular}

Fonte: elaborada pelos autores.

Tabela 5 - Distribuição de funcionários por cargo.

\begin{tabular}{lccc}
\multicolumn{1}{c}{ Cargo } & Frequência & Porcentagem & Porcentagem Cumulativa \\
\hline Assistente Técnico & 19 & 14,7 & 14,7 \\
Analista I ou correlato & 40 & 31,0 & 45,7 \\
Analista II ou correlato & 39 & 30,2 & 76,0 \\
Gerente de Núcleo ou correlato & 19 & 14,7 & 90,7 \\
Gerente Executivo & 9 & 7,0 & 97,7 \\
Presidente/Diretor & 3 & 2,3 & 100,0 \\
\hline Total & 129 & 100,0 & \\
\hline
\end{tabular}

Fonte: elaborada pelos autores. 
Tabela 6 - Distribuição de funcionários por tempo no cargo na amostra.

\begin{tabular}{cccc}
\hline Tempo no Cargo & Frequência & Porcentagem & Porcentagem Cumulativa \\
\hline Menos de 5 & 84 & 65,1 & 65,1 \\
5 a 10 & 40 & 31,0 & 96,1 \\
11 a 15 & 3 & 2,3 & 98,4 \\
15 a 20 & 1 & 0,8 & 100,0 \\
Mais de 25 & 1 & 0,8 & 100,0 \\
\hline Total & 129 & 10,0
\end{tabular}

Fonte: elaborada pelos autores.

Tabela 7 - Distribuição de funcionários por tempo de empresa na amostra.

\begin{tabular}{cccc}
\hline Tempo de Empresa & Frequência & Porcentagem & Porcentagem Cumulativa \\
\hline Menos de 5 & 40 & 31,0 & 31,0 \\
5 a 10 & 63 & 48,8 & 79,8 \\
11 a 15 & 15 & 11,6 & 91,5 \\
15 a 20 & 8 & 6,2 & 98,4 \\
21 a 25 & 1 & 0,8 & 100,0 \\
Mais de 25 & 2 & 1,6 & 100,0
\end{tabular}

Fonte: elaborada pelos autores.

Nota-se que a amostra é composta por funcionários majoritariamente entre 30 e 50 anos. Essa idade está diretamente atrelada ao tempo de empresa, maioria com mais de 5 anos dentro da organização, e a um predomínio da geração X. O tempo no cargo mostra que quase $1 / 3$ dos funcionários estão há mais de 5 anos no mesmo cargo, evidencia-se assim certa estabilidade na permanência no cargo.

Em relação ao tipo de plano previdenciário, a amostra mostra-se balanceada com $58 \%$ no plano $2 \mathrm{e}$ $42 \%$ no plano 1. Proporção similar é vista na divisão entre homens e mulheres, $55,8 \%$ e $44,2 \%$ respectivamente. Por último, a divisão entre os cargos ocupados, sendo $75 \%$ aproximadamente ocupantes de cargos de assistente e analista (posição operacional) e 25\% ocupantes de cargo de gestão,

Ao se comparar a amostra com as informações do setor de gestão de pessoas (ainda que não apresentados devido a questões legais), notou-se que a amostra reflete de forma balanceada o universo da pesquisa. 


\section{Confiabilidade e Estatística das Dimensões}

Em relação à confiabilidade do questionário, este teve o Alfa de Cronbach no valor de 0,930 , valor considerado bom, dado que quanto mais próximo de 1, melhor a consistência interna do questionário (HORA, MONTEIRO e ARICA, 2010).

Em seguida, Tabela 8, é apresentada uma estatística descritiva das cinco dimensões do medo de errar (vergonha e constrangimento - VC; desvalorização da autoestima - DA; incerteza sobre o futuro - IF; perda de interesse de semelhantes de importância - PI; afetar negativamente semelhantes de importância NA) e do índice geral (IndGeral), calculado a partir da média das respostas contidas na amostra às 25 questões do PFAl.

Tabela 8 - Estatística descritiva da amostra por dimensão.

\begin{tabular}{ccccc}
\hline Variáveis & Média & Mediana & Desvio Padrão & Variância \\
\hline VC & 0,2438 & 0,4300 & 1,02940 & 1,060 \\
DA & $-0,1744$ & 0,0000 & 0,97558 & 0,952 \\
IF & $-0,3314$ & $-0,2500$ & 0,83687 & 0,700 \\
PI & $-0,1209$ & $-0,2000$ & 0,59446 & 0,353 \\
NA & 0,0868 & 0,2000 & 0,83548 & 0,698 \\
\hline IndGeral & $-0,0003$ & 0,1200 & 0,76293 & 0,582 \\
\hline
\end{tabular}

Fonte: elaborada pelos autores.

A figura 1 ilustra as dimensões que se destacaram nas respostas contidas na amostra. Quanto mais distante do centro, maior a intensidade do medo de errar sob a perspectiva da variável específica.

Figura 1 - Média das dimensões do medo de errar na amostra

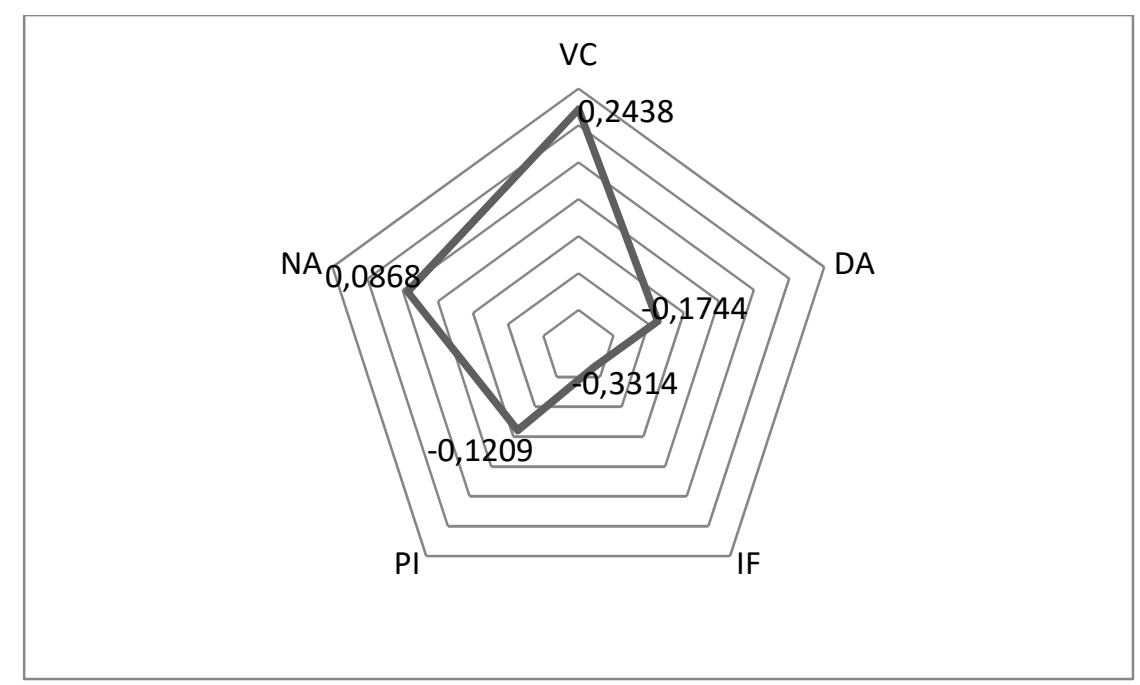

Fonte: elaborada pelos autores. 
As variáveis, cuja intensidade teve maior destaque, foram vergonha e constrangimento e afetar negativamente semelhantes de importância. Ainda que essas tenham sido as dimensões com valores positivos, os valores absolutos das cinco dimensões foram baixos, próximos ao valor central zero. Esse fato é relatado por Conroy (2001) como um fenômeno de "falso baixo" em virtude de os indivíduos não expressarem sentimentos negativos, como o medo, com naturalidade. Esse mesmo fenômeno é visto em Souza e Tomei (2015) ao estudarem o medo de errar em organizações brasileiras.

\section{Normalidade e Análise de Correlação das Dimensões do Medo de Errar}

O teste paramétrico tradicional é obtido sob a hipótese de que a população tem distribuição normal. Assim, é necessário ter certeza de que essa suposição pode ser assumida. A fim de cumprir o requisito da normalidade da distribuição dos dados, os índices do medo de errar obtidos na amostra foram testados pelo método Kolmogorof-Smirnov, os resultados são apresentados na Tabela 9.

Tabela 9 - Teste de Kolmogorov-Smirnov.

\begin{tabular}{cccccrr} 
& VC & DA & IF & PI & NA & IndGeral \\
\hline Kolmogorov-Smirnov Z & 1,299 & 1,353 & 1,338 & 0,969 & 1,687 & 0,956 \\
$P$ - valor & 0,068 & $0,051^{*}$ & $0,056^{*}$ & 0,304 & $0,007^{* *}$ & 0,320 \\
\hline
\end{tabular}

Nota: ${ }^{*} \mathrm{p}$-valor $<10 \%$, ${ }^{* *} \mathrm{p}$-valor $<5 \%,{ }^{* * *} \mathrm{p}$-valor $<1 \%$

Fonte: elaborada pelos autores.

De acordo com os resultados, no nível de significância de 5\%, apenas a dimensão NA (afetar negativamente semelhantes de importância) não segue uma distribuição normal $(0,007$ ou valor-p $<0,050)$. No nível de significância de 10\%, as dimensões DA (desvalorização da autoestima) e IF (incerteza sobre o futuro) podem ser considerados como não tendo uma distribuição normal $(0,051$ e 0,056 , respectivamente, ou seja, valor-p $<0,100$ ).

Conforme a Tabela 10, foram encontradas correlações leves entre a dimensão vergonha e constrangimento e as variáveis gênero e tipo de cargo e com a variável tempo no cargo em um nível de significância maior (1\%). A correlação com o cargo e o tempo no cargo é negativa. A dimensão desvalorização da autoestima também aparece correlacionada ao gênero e ao tempo no cargo (também negativa), esta de forma menos significativa. A correlação entre as dimensões e as gerações só aparece no nível de significância a 10\% e mesmo assim apenas para uma dimensão. Em termos de correlação, é possível inferir que mulheres em níveis hierárquicos mais baixos apresentam uma tendência a sentirem com mais intensidade o medo de errar, especialmente em relação à vergonha e ao constrangimento, bem como a diminuição da autoestima vivenciada na ocorrência do erro. De modo mais frágil, é possível afirmar que a Geração $Y$ tende a sentir com maior intensidade a dimensão vergonha e constrangimento do medo de errar. 
Tabela 10 - Tabela de correlação dimensões x variáveis demográficas.

\begin{tabular}{cccccccc}
\hline Variável & Gerações & $\begin{array}{c}\text { Faixas } \\
\text { Etárias }\end{array}$ & Gênero & Cargos & $\begin{array}{c}\text { Tipo de } \\
\text { Plano }\end{array}$ & $\begin{array}{c}\text { Tempo no } \\
\text { Cargo }\end{array}$ & $\begin{array}{c}\text { Tempo na } \\
\text { Empresa }\end{array}$ \\
\hline VC & $-0,154^{*}$ & $-0,142$ & $0,213^{* *}$ & $-0,211^{* *}$ & $0,151^{*}$ & $-0,280^{* *}$ & $-0,137$ \\
DA & $-0,118$ & $-0,119$ & $0,228^{* * *}$ & $-0,143$ & 0,062 & $-0,219^{* *}$ & $-0,129$ \\
IF & $-0,023$ & $-0,047$ & 0,101 & $-0,131$ & 0,082 & $-0,104$ & 0,015 \\
PI & 0,074 & 0,052 & 0,076 & 0,006 & 0,039 & $-0,052$ & $-0,024$ \\
NA & 0,017 & 0,073 & 0,050 & $-0,039$ & $-0,025$ & $-0,069$ & $-0,001$ \\
\hline IndGeral & $-0,063$ & $-0,055$ & $0,178^{* *}$ & $-0,153^{*}$ & 0,085 & $-0,210^{* *}$ & $-0,092$ \\
\hline
\end{tabular}

Nota: * p-valor $<10 \%$, ${ }^{* *} \mathrm{p}$-valor $<5 \%$, ${ }^{* * *} \mathrm{p}$-valor $<1 \%$

Fonte: elaborada pelos autores.

\section{Análise de Variância One-Way (ANOVA)}

Para verificar se os índices do medo de errar variam de acordo com a geração, idade (independente da geração), gênero, gênero e geração, gênero e idade, nível hierárquico, nível hierárquico e geração, nível hierárquico e idade, plano de previdência, tempo na empresa e tempo no cargo foram desenvolvidas, para cada dimensão e para o índice geral, 11 ANOVA's One-Way, uma para cada variável (ou interação) de interesse. Foi considerada uma significância de 5\%, destacados na Tabela 11.

Esses resultados corroboram os encontrados nas pesquisas de Bardage et al. (2005) e Abu-Saad e Isralowitz (1997), de que homens e mulheres apresentariam índices de medo de errar distintos, por perceberem o ambiente organizacional de maneira diferente. Esse mesmo resultado não é verificado em Souza e Tomei (2015).

As analises realizadas, consideraram os resultados expostos nas tabelas anteriores. Analisando a primeira dimensão, vergonha e constrangimento, observou-se que o gênero apresentou um efeito significativo $(p$-valor $=0,007)$, sendo que as mulheres apresentaram média mais alta.

Dentro do mesmo gênero, observou-se efeito significativo da interação com a geração e com a idade ( $p$-valor igual a 0,008 e 0,023, respectivamente). Observou-se que os homens, com o passar das gerações, diminuem a vergonha e constrangimento, enquanto as mulheres aumentam da geração $Y$ para a geração $X$, e depois diminuem na Baby Boomers.

Ainda na dimensão vergonha e constrangimento, observou-se que o tipo de plano de previdência e o tempo no cargo apresentaram efeito significativo ( $p$-valor igual a 0,033 e 0,012, respectivamente). Indivíduos que possuem o Plano 2 apresentaram maior vergonha e constrangimento. Já em relação ao tempo no cargo, esse sentimento diminui até 20 anos no cargo, porém tem um aumento grande quando se está a mais de 25 anos. 


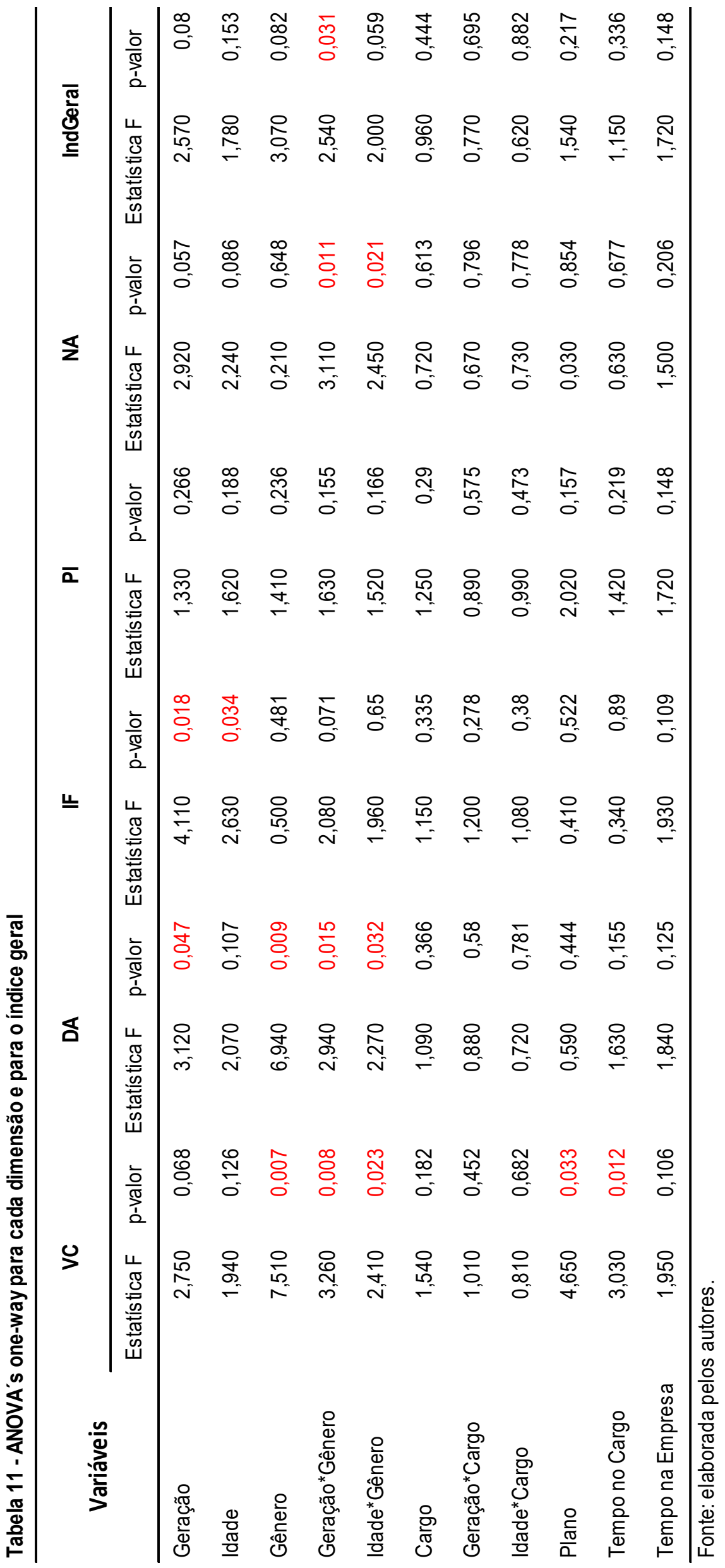


$\mathrm{Na}$ dimensão desvalorização da autoestima também se observou que o gênero teve um efeito significativo ( $p$-valor $=0,009$ ), sendo que as mulheres apresentaram índices maiores (2,99 contra 2,60 dos homens). Observou-se ainda que, dentro do mesmo gênero, houve efeito significativo da interação com a geração e com a idade (p-valor igual a 0,015 e 0,032). Para ambos os sexos, observou-se que a geração que apresentou os maiores índices para desvalorização da autoestima foi a Geração X (média de 2,71 para homens e 3,14 para mulheres).

Ainda na dimensão desvalorização da autoestima observou-se que o gênero, sozinho, apresentou um efeito significativo ( $p$-valor $=0,047$ ), sendo que os homens apresentaram índices menores que as mulheres $(2,60$ contra 2,99$)$.

A geração e a idade apresentaram um efeito significativo na terceira dimensão, incerteza sobre o futuro, com p-valor igual a 0,018 e 0,034, respectivamente. Observou-se que os índices aumentam da Geração X para Geração Y, mas depois diminuem nos Baby Boomers (2,23, 2,80 e 2,41, respectivamente).

Na quinta dimensão, afetar negativamente semelhantes da importância, observou-se que o gênero, sozinho, não apresenta efeito significativo. Porém, dentro do mesmo gênero, observou-se efeito significativo da interação com a geração e com a idade (p-valor igual a 0,011 e 0,021, respectivamente). Observou-se que os homens, com o passar das gerações, diminuem o índice afetar negativamente semelhantes da importância, enquanto as mulheres aumentam da geração $\mathrm{Y}$ para a geração $\mathrm{X}$, e depois diminuem na Baby Boomers.

No índice geral observou-se que o gênero, sozinho, não apresenta efeito significativo. Porém, dentro do mesmo gênero, observou-se efeito significativo da interação com a geração ( $p$-valor igual a 0,031 ). Observou-se que os homens, com o passar das gerações, diminui o índice geral, enquanto as mulheres aumentam da geração Y para a geração X, e depois diminuem na Baby Boomers.

Esses resultados de diferença nas dimensões de medo em relação a geração vão de encontro aos resultados de Souza e Tomei (2015), que não verificaram diferença entre as diferentes gerações em seu estudo. Na dimensão perda de interesse, nenhuma das variáveis em estudo apresentou um efeito significativo.

Conforme observado na Tabela 11, apenas nas dimensões DA e IF a geração apresentou um efeito estatisticamente significativo. Na dimensão DA, as Gerações $X$ e $Y$ podem ser consideradas estatisticamente iguais, mas são estatisticamente diferentes dos Baby Boomers (média igual a 2,33). Na dimensão IF, a Geração $Y$ pode ser considerada estatisticamente diferente das demais (média igual a 2,23), uma vez que seu intervalo de confiança não está contido no intervalo das demais gerações. Já as Gerações X e Baby Boomers podem ser consideradas estatisticamente iguais, uma vez que seus intervalos de confiança se contêm.

Já em relação à idade, conforme observado na Tabela 11, foi observado um efeito significativo apenas na dimensão IF. Os mais jovens, entre 21 e 30 anos, foram os que apresentaram a menor média $(2,23)$ e essa foi a única média que foi estatisticamente diferente das demais, uma vez que seu intervalo de confiança é o único que não está contido nos demais.

Nas demais dimensões, a geração e a faixa etária não apresentaram efeito significativo, e dessa forma não é possível afirmar que há diferentes médias entre as gerações e faixas etárias, para cada dimensão.

Indo de encontro a teoria (Crawford e Mills, 2011; Blacker, 1992), o cargo do indivíduo não influenciou a percepção do medo dos indivíduos, corroborando os resultados de Souza e Tomei (2015). 


\section{CONCLUSÕES}

Este trabalho propôs analisar como a intensidade do medo de errar varia segundo as diferentes gerações presentes no ambiente organizacional de um Fundo de Pensão. Secundariamente, a intensidade do medo de errar também foi avaliada em relação ao gênero, tipo de plano de previdência, tipo cargo, tempo no cargo e na empresa.

Apenas nas dimensões desvalorização da autoestima e incerteza sobre o futuro a geração apresentou um efeito estatisticamente significativo, considerando a aplicação das ANOVA's. A Geração X apresentou os maiores índices para essas dimensões. A Geração $Y$ apresentou o menor índice para a dimensão incerteza sobre o futuro, fato também apresentado na faixa etária entre 21 e 30 anos. Os Baby Boomers apresentaram o menor índice na dimensão desvalorização da autoestima. Baby Boomers são confiantes realizadores de tarefas e não gostam de feedback constante (TOLBIZE, 2008), o que pode explicar um menor temor nessa dimensão. Pode-se dizer que a Geração X, maioria no Fundo de Pensão, apresentou a maior intensidade do medo de errar. Os índices mais baixos em relação à Geração $\mathrm{Y}$ podem estar relacionados à elevada confiança dessa geração em sua competência profissional e seu apreço pelo desenvolvimento da carreira, aspectos ressaltados por Glass (2007) ao descrever o perfil dessa geração.

A correlação entre as dimensões e as gerações só aparece no nível de significância a 10\% e mesmo assim apenas para uma dimensão vergonha e constrangimento. A análise de correlação indicou, embora de forma suave, que o medo de errar é mais intenso em relação às variáveis gênero, nível hierárquico e tempo no cargo. Homens e mulheres têm percepções diferentes em relação ao medo. Além disso, quanto maior o nível hierárquico, menor a intensidade do sentimento. É possível inferir que mulheres em níveis hierárquicos mais baixos apresentam uma tendência a sentirem com mais intensidade o medo de errar, especialmente em relação à vergonha e ao constrangimento, bem como a diminuição da autoestima vivenciada na ocorrência do erro, reforçando a premissa levantada no referencial teórico (BARRETO, 2000).

Através das ANOVA's desenvolvidas também foi possível observar que o gênero, tanto sozinho como interagindo com a geração e a idade, apresentou um efeito estatisticamente significativo nas dimensões vergonha e constrangimento e desvalorização da autoestima, sendo que os homens apresentaram os menores índices. Esses resultados corroboram os encontrados em outros estudos (BARDAGE et al., 2005; ABU-SAAD e ISRALOWITZ, 1997). Gênero e geração apresentaram um efeito significativo em afetar negativamente semelhantes de importância, bem como no Índice Geral. O tipo de plano de previdência e o tempo no cargo apresentaram um efeito significativo na dimensão vergonha e constrangimento, sendo que o Plano 2 apresentou os maiores índices e os índices vão diminuindo conforme aumenta o tempo de cargo até os 20 anos. Curiosamente, os maiores índices de vergonha e constrangimento foram apresentados em quem está a mais de 25 anos no cargo, quando analisado separadamente.

Aspectos relacionados ao contexto da cultura organizacional do Fundo de Pensão certamente influenciaram os índices do medo de errar, como o tipo de vínculo empregatício, a relativa estabilidade de emprego, a diferença entre os tipos de planos de previdência, a estrutura de cargos e salários, dentre outros elementos que por certo não foram abordados nesse estudo. Porém, não é possível vincular um determinado aspecto como fator determinante na intensidade do medo de errar. 
Este estudo pode ajudar não só o Fundo de Pensão, mas outras organizações a melhor enfrentarem os desafios impostos pela gestão de pessoas. Pode auxiliar na aplicação de políticas de recursos humanos eficientes e que atendam as expectativas de seus funcionários. Como sugestão para pesquisas futuras, o estudo sobre o sentimento do medo de errar pode ser ampliado para diferentes tipos de empresas, contribuindo para o entendimento desse sentimento no contexto organizacional.

\section{REFERÊNCIAS}

ABU-SAAD, I.; ISRALOWITZ, R. E. Gender as a determinant of work value among university students in Israel. Journal of Social Psychology, v. 137, n. 6, p. 749-763, 1997.

ABRAPP. ASSOCIAÇÃO BRASILEIRA DAS ENTIDADES FECHADAS DE PREVIDÊNCIA COMPLEMENTAR. Página eletrônica. Brasil. Disponível em: <http://www.abrapp.org.br/Consolidados/Consolidado_Estatistico_2013_12.pdf>. Acesso em: julho de 2016.

ANDREWS, B. Bodily shame as a mediator between abusive experiences and depression. Journal of Abnormal Psychology. v. 104, p. 277-285, 1995.

APPLEBAUM S. H.; BREGMAN M.; MOROZ P. Fear as a strategy: effects and impact within the organization. Journal of European Industrial Training, v. 22, n.3, p. 113-127, 1998.

ARONSON, E.; WILSON, T. D.; AKERT, R. M. Psicologia Social. 3 ed. Rio de Janeiro: LTC, 2012.

BANCO CENTRAL DO BRASIL, Resolução n 3.792 de 24 de setembro de 2009. Disponível em: http://www.bcb.gov.br/pre/normativos/res/2009/pdf/res_3792_v3_P.pdf. Acesso em 20 de julho de 2016.

BARDAGE, C; PLUIJIM, S. M. F.; PEDERSON, N. L.; DEEG, D. J. H; JYLHA, M.; NOALE, M.; BLUMSTEIN, T.; OTERO, A. Self-rated health among older adults: a cross-national comparison, European Journal of Ageing, v. 2, n. 2, p. 149-158, 2005.

BARRETO, M. Danos da humilhação à saúde. Assédio Moral. 2000. Disponível em: <http://www.assediomoral.org> . Acesso em: 15 dez. 2013.

BIRNEY, R. C.; BURDICK, H.; TEEVAN, R. C. Fear of Failure. New York: Van Nostrand, 1969.

BLACKER, F. Formative contexts and activity systems: postmodern approaches to the management of change. In: REED, M.; HUGHES, M. (eds) Rethinking Organization: New Directions in Organization Theory and Analysis, p. 273-94. London, Newbury Park, CA and New Delhi: Sage, 1992.

CARVALHAL, A. Governança Corporativa e Sucesso Empresarial: Melhores Práticas para Aumentar o Valor da Firma. São Paulo: Saraiva, 2006.

CASTELHANO, L. M. O Medo do Desemprego e a(s) Nova(s) Organizações de Trabalho, 2005 Dissertação (Mestrado em Psicologia), Pós-graduação em Psicologia Social, Pontifícia Universidade Católica de São Paulo, São Paulo, 2005

CONROY, D. E. Multidimensional Fear of Failure Measurement: The Performance Failure Appraisal Inventory. Journal of Applied Sport Psychology, v. 14, p. 76-90, 2002.

. Progress in the development of a multidimensional measure of fear of failure: The Performance Failure

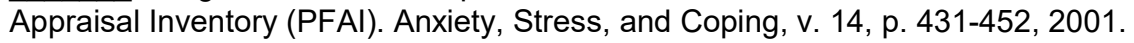

; ELLIOT, A. J. Fear of failure and achievement goals in sport: Addressing the issue of the chicken and the egg. Anxiety, Stress, and Coping: An International Journal, v. 17, p. 271-285. 2004.

;; PINCUS, A. L. The expression of achievement motives in interpersonal problems. Journal of Personality, v. 77, n. 2, p. 495-526, 2009.

CRAMPTON, S. M.; HODGE, J. W. Generation Y: Unchartered Territory. Journal of Business \& Economics Research, v. 7, n. 4, 2009.

CRAWFORD, J. B.; MILLS, A. J. The Formative Context of Organizational Hierarchies and Discourse: Implications for Organizational Change and Gender Relations, Gender, Work and Organization, v. 18, n. 1, 2001.

CUNHA, E. G. A Gestão do Medo como Instrumento de Coerção nas Organizações Públicas. UFRGS. 2006

DANCEY, Christine P; REIDY, John. Estatística sem matemática para psicologia. Porto Alegre: Penso, 2013.

DAY, J. P. The Anatomy of Hope and Fear. Mind, v. 79, n. 315, p. 369-384. 1970.

DEJOURS, C.. A loucura do trabalho: estudo de psicopatologia do trabalho. São Paulo: Cortez - Oboré, 1992.

DULEY, A. R.; CONROY, D. E.; MORRIS, K.; WILEY, J.; JANELLE, C. M. Fear of failure biases affective and attentional responses to lexical and pictorial stimuli. Motivation and Emotion, v. 29, n. 1, p. 1-17. 2005. 
ELLIOT, A. J. The Intergenerational Transmission of Fear of Failure. Personality and Social Psychology Bulletin, v. 30, n. 8, p. 957-971. 2004.

.; $\mathrm{CHURCH}, \mathrm{M}$. A. A hierarchical model of approach and avoidance achievement motivation. Journal of Personality and Social Psychology, v. 72, p. 218- 232, 1997.

; McGREGOR, H. A. Test anxiety and the hierarchical model of approach and avoidance achievement motivation. Journal of Personality and Social Psychology, v. 76, p. 628-644, 1999.

FAIRCHILD, R. Emotions in the Financial Markets, in Investor Behavior: The Psychology of Financial Planning and Investing (eds H. K. Baker \& V. Ricciardi), John Wiley \& Sons, Inc., Hoboken, NJ, USA, 2014.

FONSECA, N. F., BRESSAN, A. A., IQUIAPAZA, R. A., GUERRA, J. P. Análise do Desempenho Recente de Fundos de Investimento no Brasil, Contabilidade Vista \& Revista, vol. 18, n. 1, p. 95-116, 2007.

FRIJDA, N. H. Psychologists point of view. In: LEWIS, M.; HAVILAND-JONES, J. Handbook of Emotions, 2nd ed. New York: Tue Guilford Press, 2000.

GAULEJAC, V. As origens da vergonha. São Paulo: Via Lettera, 2006.

GIL, A. C. Como Elaborar Projetos de Pesquisa. 4ª ed. São Paulo: Atlas, 2002.

GILLEY, K. A alquimia do medo. São Paulo: Editora Cultrix, 1999.

GLASS, A. Understanding Generational Differences for Competitive Success. Industrial and Commercial Training, v.39, n.2, p.98-103, 2007.

HORA, H R. M. da; MONTEIRO, G. T. R.; ARICA, J.. Confiabilidade em Questionários para Qualidade: Um Estudo com o Coeficiente Alfa de Cronbach. Produto \& Produção, vol. 11, n. 2, p. 85 - 103, jun. 2010

JORGENSEN, B. Baby Boomers, Generation X and Generation Y: Policy implications for defense forces in the modern era. Foresight, v. 5, n. 4, p. 41-49, 2003.

JURKIEWICZ, C. E.; BROWN, R.G.. GenXers vs. boomers vs. matures: Generational comparisons of public employee motivation. Review of Public Personnel Administration, 18, 18-37, 1998.

KOURY, M. G. P. Medo e sociabilidade. Revista de antropologia experimental, n. 2, p.1-12, 2002.

LEWIS, M. Shame: The exposed self. New York: Free Press, 1992.

LÓPEZ, E. M. Quatro Gigantes da Alma. 22. ed. Rio de Janeiro: José Olympio. 1972.

McCLELLAND, D. C.; ATIKINSON, J. W.; CLARK, R. A.; LOWELL, E. L. The achievement motive. East Norwalk, Connecticut: Appleton-Century-Crofts, 1953.

MURRAY, H. Explorations in Personality. New York: Oxford University Press, 1938.

OLIVEIRA, S. O Nascimento de uma nova Versão de Líderes. São Paulo: Integrare Editora, 2010.

PEREIRA, M. L. J. de B. Modelos de Mudança nas Organizações Brasileiras: uma análise crítica. In: BJUR, W.; CARAVANTES, G. R. (Orgs.). Reengenharia ou readministração? Do útil e do fútil nos processos de mudança. (p.108159). Porto Alegre: AGE, (1995).

PEREIRA, M. A. O Medo no Contexto Organizacional, 2006, 103f. Dissertação (Mestrado em Administração Pública) Escola Brasileira de Administração Pública e de Empresas, Fundação Getulio Vargas, Rio de Janeiro, 2006.

RIEZLER, K. The Social Psychology of Fear. The American Journal of Sociology. v. 49, n. 6, p. 489-498, 1944.

SARTRE, J. P. Esboço para uma teoria das emoções. Porto Alegre: Coleção L \& Pocket Plus. 2010.

SBICIGO J. B; BANDEIRA D. R; DELL'AGLIO, D. D. Escala de Autoestima de Rosenberg (EAR): validade fatorial e consistência interna. Psico-USF, v. 15, n. 3, p. 395-403, 2010.

SELIGMANN-SILVA, E.. Desgaste Mental do Trabalho. São Paulo: Cortez Editora, 1994.

SEYMOR, E. Personality: basic issues and current research. New Jersey: Prentice-Hall. 1980.

SOUSA, L. B; GODOI C. K., VERDINELLI, M. A. Estados Afetivos no Local de Trabalho: Um Estudo Multi-Nível. In. Encontro de Gestão de Pessoas e Relações de Trabalho, 1, 2007. Anais... Natal: ENGPR, 2007.

SOUZA, D; TOMEI, P. A. Fear of Failure in the Workplace - an exploratory study about fear in Brazilian organizations, In. Asamblea anual del Consejo Latinoamericano de Escuelas de Administración, 50, 2015. Anais... Viña del Mar: CLADEA, 2015.

SUARÉZ, J. G. Managing Fear in the Workplace. Washington, D.C.: Office of the Under Secretary of the Navy, Total Quality Leadership Office, 93-01, 1993.

TOLBIZE, A. Generational differences in the workplace. Research and Training Center on Community Living, University of Minnesota, Minneapolis, 2008. 
TOMKIEWICZ, J; BASS, K. Attitudes of business students toward management generation cohorts. North American Journal of Psychology, v. 10, n.2, 435-443, 2008.

VELOSO, E. F. R.; DUTRA, J.S.; NAKATA, L.E. Percepções sobre carreiras inteligentes: diferenças entre as gerações Y, X e Baby Boomers. In. Encontro Nacional da Associação Nacional de Pós-graduação e Pesquisa em Administração, 32, 2008. Anais... Rio de Janeiro: ANPAD, 2008.

WILSON, L.; EDMODSON, A. Deming's elusive eighth point: Why you can never drive fear out of the organization and what to do about it. Minneapolis, St. Paul: Pecos River Learning Centers, 1991. 